\title{
Formação continuada: visão dos gestores de creche na região de Presidente Prudente/SP
}

\author{
Carolina Foschi Christo* \\ Bruna Omito Ferreira** \\ Célia Maria Guimarães***
}

*Graduada em Letras pela Universidade do Oeste Paulista (Unoeste) e em Pedagogia pela Faculdade de Ciências e Tecnologia da (FCT) da Universidade Estadual Paulista (Unesp), integrante do grupo de Pesquisa Profissão docente: formação, identidade e representações sociais. Participante do Forpedi e como bolsista Proex durante o ano de 2011.

E-mail: carolfoschi@yahoo.com.br

**Graduanda em Pedagogia pela FCT/ Unesp. Participante do Forpedi e como bolsista Proex durante o ano de 2012.

E-mail: bruna_omito@hotmail.com

***Pós-doutoranda pela Universidade de Lisboa (UL-PT). Doutora em Educação pela Faculdade Filosofia e Ciências (FFC)/ Unesp. Professora do Departamento de Educação e da pós-gradução em Educação da FCT/ Unesp. Líder do subgrupo de pesquisa Educação Infantil, vinculado ao Grupo de Pesquisa Profissão docente: formação, identidade e representações sociais. Ex-coordenadora do Fórum Regional Permanente de Educação da Infância.

E-mail: celiamguimaraes@terra.com.br
Resumo: 0 presente texto tem como objetivo analisar a visão que gestores de creches municipais apresentam sobre formação continuada. Os resultados parciais são um recorte do projeto “(Des)caminhos da educação da infância na região de Presidente Prudente - SP: políticas necessárias para um atendimento de qualidade", vinculado ao Fórum Regional Permanente de Educação da Infância (Forpedi), sob a anuência da União dos Dirigentes Municipais de Educação (Undime). A análise do presente trabalho foi feita através de dados que foram obtidos por meio de questionários respondidos por 76 dos 85 participantes, em abril de 2013. Posteriormente, os dados foram tabulados e organizados em categorias para análise. Para esta comunicação, selecionamos a questão: Formação continuada é...?

Palavras-chave: Formação continuada. Gestores. Creche. 
A instalação do Fórum Regional Permanente de Educação da Infância (Forpedi) ocorreu em 22 de abril de 2008, num evento específico, na Faculdade de Ciências e Tecnologia (FCT) da Universidade Estadual Paulista (Unesp), campus de Presidente Prudente.

Na ocasião, além da instalação do Forpedi, com a aprovação dos princípios e objetivos deste pela plenária, a programação contou com uma mesaredonda coordenada pela profa. dra. Célia Maria Guimarães, da FCT/Unesp Presidente Prudente sobre o tema: "Educação da infância: direitos, qualidade e o compromisso dos fóruns", com a participação da profa. dra. Maristela Angotti, da Faculdade de Ciências e Letras ( $F C L) /$ Unesp Araraquara e Fórum Paulista de Educação Infantil, e da profa. dra. Elisabeth Gelli Yazlle, da FCL/ Unesp Assis e Fórum Paulista de Educação Infantil.

Ainda em 2008, o Forpedi realizou duas conferências, sendo uma sobre “Educação infantil e ensino fundamental: interlocução entre avaliação e a formação de professores", sob a responsabilidade das professoras doutoras Zilma Ramos de Moraes, da Universidade de São Paulo (USP) e Emília Cipriano Sanches, da Pontifícia Universidade Católica de São Paulo (PUCSP) e mediação da professora doutora Gilza Maria Zauhy Garms; e outra conferência intitulada "A especificidade da educação infantil e as implicações para o ensino fundamental de nove anos: o que podemos aprender com as experiências internacionais?", proferida pela professora doutora Lenira Haddad, da Universidade Federal de Alagoas.

Em 2009, juntamente com a União dos Dirigentes Municipais de Educação (Undime), foi realizado um levantamento do perfil das redes municipais e, em parceria com o Conselho Municipal de Educação (Comed) de Presidente Prudente, foi promovido também o fórum de discussão “Indagações sobre currículo: a concepção de currículo e seus desdobramentos”.

No ano de 2010, os esforços foram concentrados no sentido de discutir os dados referentes ao levantamento do perfil das redes municipais e organizar as informações a fim de promover um trabalho de formação voltado às necessidades apontadas pelos 32 municípios ${ }^{1}$ vinculados aos polos regionais da Undime de Presidente Prudente e Presidente Epitácio - SP.

Alguns dos 32 municípios: Anhumas; Caiabu; Caiuá; Emilianópolis; Estrela do Norte; Euclides da Cunha; lepê; Indiana; Marabá Paulista; Martinópolis; Mirante do Paranapanema; Narandiba; Piquerobi; Pirapozinho; Presidente Epitácio; Presidente Prudente; Presidente Venceslau; Rancharia; Regente Feijó; Ribeirão dos Índios; Rosana; Santo Anastácio; Santo Expedito; Taciba; Tarabai; Teodoro Sampaio. 
Detectadas as reais necessidades das redes municipais, em março de 2011, o Forpedi iniciou um projeto de formação continuada com a temática a creche em foco, cuja proposta foi desenvolver uma política pública de formação contínua dos profissionais que atuam nas creches, tendo como objetivo maior tornar 0 atendimento das crianças na creche uma ação que respeita os direitos constitucionais da criança e de sua família. A opção pela educação infantil, em especial a creche, que atende a criança na faixa etária de 0 a 3 anos, teve como motivo os resultados das avaliações e reflexões realizadas em conjunto com os responsáveis pela gestão desse segmento nos municípios envolvidos, os quais apontaram a necessidade de uma atenção sistemática à creche. 0 desenvolvimento do projeto prevê encontros mensais que reúnem gestores, entre diretores, supervisores, coordenadores e dirigentes municipais. Não se trata de um curso, mas de formação contínua, com o objetivo de promover ações no âmbito das políticas de atendimento nas creches dos municípios participantes. Para iniciar, o foco, ao longo do ano de 2011, foi a discussão sobre a visão e os conhecimentos que os gestores têm sobre a criança, a creche e o papel dos adultos que atuam diretamente com as crianças, bem como sobre o cuidado e a educação das crianças no espaço da creche.

0 trabalho encontra-se em continuidade e tem como meta construir uma proposta pedagógica e curricular que respeite a criança e a especificidade do seu modo de agir, pensar e aprender, além de discutir a valorização do profissional da creche (estatuto, plano de carreira, condições de trabalho etc.).

Assim sendo, desde 2008, o fórum vem realizando reuniões periódicas do grupo gestor; participação nas reuniões da Undime, polo de Presidente Prudente e Presidente Epitácio; levantamento de dados referentes à educação da infância em Presidente Prudente e região; censo dos profissionais das redes municipais de ensino de Presidente Prudente e região; participação em encontros e seminários, sempre em consonância com os princípios e metas estabelecidos por este fórum, que tem como objetivo proporcionar aos gestores dos municípios envolvidos as ferramentas necessárias para obter informação sobre a realidade do atendimento à criança e sua família, considerando seus problemas, dificuldades, possibilidades e sucessos. Com base nos dados levantados, os gestores coordenarão o processo de planejamento participativo em seus municípios, a fim de delinear as causas dos problemas encontrados. 0 passo seguinte é a elaboração do plano de ações políticas e pedagógicas com vistas à solução das dificuldades apontadas, de forma que resultem na melhoria da qualidade do atendimento da criança de 0 a 3 anos, no qual deve 
estar prevista também uma sistemática de formação continuada. A próxima etapa será estender essa ação

aos anos pré-escolares e anos iniciais do ensino fundamental. A meta é assegurar o acesso da população infantil a um atendimento educacional de qualidade, bem como fortalecer esse campo de conhecimentos e de atuação profissional na região de Presidente Prudente - SP, juntamente com os signatários da Carta de Campinas, aprovada em 15 de agosto de 2013. Os fóruns estaduais presentes no VI Encontro Regional Sudeste do Mieib Fórum Permanente de Educação Infantil do Espírito Santo, Fórum Mineiro de Educação Infantil, Fórum Paulista de Educação Infantil e Fórum Permanente de Educação Infantil do Rio de Janeiro - compactuam e ratificam a luta do Movimento Interfóruns de Educação Infantil (Mieib) no sentido de resistir às políticas que vão na contramão das conquistas na área da educação infantil, ressaltando-se as tensões relacionadas à Conferência Nacional de Educação (Conae), de 2014. Neste sentido, o Forpedi destaca seu posicionamento e reivindicações propostas pelos órgãos acima e inclui pontos de seu interesse às instituições abaixo:

\section{Ao Ministério da Educação (MEC)}

- Ampliar, em regime de colaboração, políticas públicas que garantam o acesso das crianças de 0 a 5 anos de idade à educação infantil.

- Expandir políticas públicas de financiamento, ampliando os recursos do Fundo de Manutenção e Desenvolvimento da Educação Básica e de Valorização dos Profissionais da Educação (Fundeb) para compra de materiais pedagógicos para educação infantil (brinquedos, jogos, CDs, DVDs, livros de literatura infantil, poemas, instrumentos sonoromusicais e quaisquer outras produções regionais). Disponibilizar variedade de material de apoio e orientação ao trabalho do gestor pedagógico e dos professores.

- Orientar os municípios a buscar como referência os documentos produzidos pela Coordenação de Educação Infantil (Coedi)/MEC na construção dos seus currículos para a educação infantil, posicionandose contra o uso de recursos públicos na adoção de sistemas educacionais apostilados em instituições de educação infantil.

- Fortalecer, em regime de colaboração, políticas públicas permanentes de formação inicial e continuada de professores/as e demais profissionais da educação que atuam na educação infantil.

- Assumir o Custo Aluno Qualidade Inicial (CAQi) como referência para a definição do custo-aluno qualidade na educação infantil. 
- Relevar a concepção de infância e da legislação educacional em vigor na elaboração de políticas públicas em âmbito nacional, estadual e municipal na elaboração e orientação de políticas referentes à avaliação na educação infantil.

- Subsidiar pesquisas com foco na criança e na diversidade (quilombolas, indígenas, ribeirinhas, do campo e da zona urbana central e periférica, educação especial).

\section{Ao Conselho Nacional de Educação (CNE)}

- Reafirme no parecerno 17/2012 que se exija para o exercício da docência na educação infantil a formação em nível superior - licenciatura plena em Pedagogia, conforme as disposições transitórias contidas no artigo 67 da Lei de Diretrizes e Bases da Educação Nacional (LDBEN), de 1996, que deu prazo de dez anos desde a sua aprovação para que todos os profissionais que ainda não tivessem formação em nível superior a realizassem nesse período.

- Retire do parecer ( $n$ - 17/2012) qualquer possibilidade de contratação ou abertura de concurso público para a figura de auxiliar (outras denominações) ou aquele que dará suporte ao professor/a, pois a defesa é que no desenvolvimento do trabalho pedagógico seja sempre o/a professor/a para evitar a fragmentação entre o cuidar e o educar.

- Posicionar-se contrariamente ao uso de recursos públicos na adoção de regimes apostilados em instituições de educação infantil em seus sistemas educacionais.

- Recomendar que os documentos produzidos pelo MEC/Coedi sejam referência na construção dos currículos para a educação infantil.

- Reafirmar a creche enquanto instituição educacional diurna de forma a ressaltar a indissociabilidade do cuidar/educar.

\section{Ao Conselho Estadual de Educação (CEE)}

- Respeitar e fazer cumprir, em nível municipal e estadual, a data base do corte etário (31/03) para ingresso na pré-escola e no ensino fundamental, conforme as resoluções no 01/2010 e nํㅜ 06/2010 do Conselho Nacional de Educação.

- Alterar a Deliberação CEE/SP 111/2012 de forma a incluir nos cursos de Licenciatura em Pedagogia a Formação Docente de Creche (0 a 3 anos) e de Educação Especial.

Aos Conselhos Municipais de Educação (Comed)

- Respeitar e garantir, em nível municipal e estadual, a data base do corte etário (31/03) para ingresso na pré-escola e no ensino fundamental, 
conforme as resoluções nํㅜ 01/2010 e nํ06/2010 do Conselho Nacional de Educação.

\section{À União dos Dirigentes Municipais de Educação (Undime) e ao Conselho Nacional de Secretários de Educação (Consed)}

- Cumprir as leis que tratam da valorização dos/as profissionais da educação, destacando-se: o Art. 61, da Lei 9.394/96, alterado pela Lei 12.014, de 6/08/2009; a Resolução nํ5/2009, DCNEl; os pareceres CNE n² 21/2008 e n²6/2008.

- Efetivar as políticas públicas de educação infantil atendendo às especificidades de cada contexto (quilombolas, das diferentes etnias indígenas, ribeirinhas, do campo e da zona urbana central e periférica) e respeitar as legislações específicas quanto à educação étnico-racial e afro-brasileira, indígena, educação do campo e educação inclusiva.

- Respeitar e garantir, em nível municipal e estadual, a data base do corte etário para ingresso na pré-escola e no ensino fundamental, conforme as resoluções nํㅜ 01/2010 e nํㅜ 06/2010 do Conselho Nacional de Educação.

- Posicionar-se de forma contrária ao uso dos recursos públicos na adoção de sistemas educacionais apostilados em instituições de educação infantil.

- Promover políticas públicas em regime de colaboração, que garantam a formação inicial e continuada de professores/as e demais profissionais da educação que atuam na educação infantil.

- Garantir a presença do professor na educação infantil, promovendo a indissociabilidade entre o educar e o cuidar.

- Exigir nos concursos públicos dos municípios e estados o curso de graduação de Licenciatura em Pedagogia para o ingresso na carreira de professor da educação infantil.

- Reafirmar a manutenção nas planilhas do Censo Escolar da indicação das faixas etárias de 0 a 3 anos e de 4 a 5 anos de idade.

- Exigir do Fundo Nacional de Desenvolvimento da Educação (FNDE) a adoção do CAQi como parâmetro para a definição do custo-aluno qualidade na educação infantil, mediante revisão criteriosa do valor de referência.

- Garantir que o processo de municipalização da educação infantil se dê com base em regime de colaboração, efetivando a corresponsabilidade entre os entes federados, de forma a assegurar a qualidade necessária à oferta de atendimento.

- Cumprir o piso salarial nacional dos/as profissionais da educação 
básica pelos municípios, assegurando hora/atividade para os/as profissionais da educação infantil, conforme legislação.

- Conceder vagas para o Mieib, nos fóruns federal, estadual e municipal de educação, para que possam participar da Conae/2014 e na construção, nos estados e municípios, dos planos municipal, estadual e nacional de educação.

\section{À União dos Conselhos Municipais de Educação (Uncme) e ao Fórum Nacional dos Conselhos Estaduais de Educação (FNCEEs)}

- Posicionar-se de forma contrária ao uso dos recursos públicos na adoção de sistemas educacionais apostilados em instituições de educação infantil.

- Apoiar a representação dos fóruns estaduais de educação infantil nos conselhos municipais e estaduais de educação.

- Exigir nos concursos públicos dos municípios e estados o curso de graduação de Licenciatura em Pedagogia para o ingresso na carreira de professor da educação infantil.

- Respeitar e garantir, em nível municipal e estadual, a data base do corte etário (31/03) para ingresso na pré-escola e no ensino fundamental, conforme as resoluções nํㅜ 01/2010 e nํㅜ 06/2010 do Conselho Nacional de Educação.

- Ratificar nas legislações específicas e/ou complementares, de sua competência, os critérios de qualidade estabelecidos nos Parâmetros Nacionais de Qualidade da Educação Infantil, quanto à infraestrutura, número de crianças por $\mathrm{m}^{2}$ da sala de referência, e professores/as com formação para autorizar a abertura e o funcionamento de instituições de educação infantil públicos e privados.

- Monitorar o cumprimento da "obrigatoriedade da matrícula" a partir dos 4 anos nas redes públicas e privadas de educação infantil.

\section{Ao Fundo Nacional de Educação (FNE)}

- Que retomem o debate da Conae/2010 sobre a data de corte de 31/03 para ser garantido em lei.

\section{Aos fóruns que compõem a Região Sudeste}

- Que pleiteiem assento nos conselhos municipais e estaduais de educação de modo a reforçar a luta pelo respeito à especificidade da criança e, neste momento, em particular, para a participação na Conae/2014.

- Que pleiteiem assento nos fóruns municipais e estaduais de educação de modo a reforçar a luta pelo respeito à especificidade da criança. 


\section{Ao Congresso Nacional}

- Aprovar o Plano Nacional de Educação respeitando os princípios e a função da educação infantil, presente na LDBEN no 9.394/96 e nas Diretrizes Curriculares Nacionais para a Educação Infantil (Res. CNE/ CEB nํㅜ 5, de 17 de dezembro de 2009).

- Definir a aplicação dos $10 \%$ do Produto Interno Bruto (PIB) para a educação pública.

- Aprovar projetos de lei para a educação infantil coerentes com o disposto na Constituição Federal/88, na LDBEN no 9.394/96, nas Diretrizes Curriculares Nacionais para a Educação Infantil (Res. CNE/ CEB $n$ ㅇ 5, de 17 de dezembro de 2009) e em toda a legislação nacional que referenda a educação infantil, como primeira etapa da educação básica, rejeitando qualquer proposta que venha a ferir estes princípios.

\section{Ao Ministério Público}

- Impugnar os editais de concursos públicos para professor da educação infantil que não atendam às exigências da LDBEN no 9.394/96.

- Fazer cumprir a Constituição Federal/1988, a LDBEN no 9.394/96 e toda a legislação nacional, que referenda a educação infantil de 0 até 5 anos de idade como primeira etapa da educação básica, ofertada em instituições educacionais e regulamentada e autorizada pelos sistemas de ensino.

- Reconhecer e fazer cumprir o corte etário para ingresso na pré-escola e no ensino fundamental conforme as resoluções $n-0$ 01/2010 e n은 06/2010 do Conselho Nacional de Educação, que determinam a idade de corte aos 6 anos de idade completos até 31 de março do respectivo ano em que a criança ingressa no ensino fundamental.

\section{Ao Instituto Nacional de Estudos e Pesquisas Educacionais (Inep)}

- Manter nas planilhas do Censo Escolar/Inep a indicação das faixas etárias de 0 a 3 anos e de 4 a 5 anos de idade.

- Respeitar a concepção de infância e da legislação educacional em vigor na elaboração de políticas públicas em âmbito nacional, estadual e municipal na elaboração e orientação de políticas referentes à avaliação na educação infantil.

- Subsidiar pesquisas que tenham como foco a criança na sua diversidade (quilombolas, indígenas, ribeirinhas, da educação especial, do campo e da zona urbana central e periférica). 
Desde a instalação do Forpedi em Presidente Prudente, a formação continuada de gestores de creches públicas não era abordada sistematicamente na região do Oeste Paulista, nomeadamente entre os 32 municípios vinculados aos polos regionais de Presidente Prudente e de Presidente Epitácio da Undime. O Forpedi desenvolve uma proposta de formação continuada de gestores de creche que aborda os elementos da gestão democrática e da organização do trabalho pedagógico na creche, o que intenciona auxiliar os profissionais no cumprimento das duas funções indissociáveis, o cuidar e o educar.

Com a LDBEN no 9.394/96, os municípios convivem com a exigência/ necessidade da formação mínima docente, da organização do plano de carreira dos profissionais, como também enfrentam o desafio da elaboração e execução de projetos de formação continuada e da construção de um projeto pedagógico específico para a educação infantil. Campos, Fullgraf e Wiggers (2006) afirmam que, embora desde 1990 muitas medidas tenham contribuído para mudanças significativas no atendimento infantil, ainda existe um distanciamento entre o que prevê a legislação brasileira e as experiências das crianças e adultos na maioria da educação infantil. O reconhecimento pelo governo municipal para o que os autores alertam e sua tradução em iniciativas pelos gestores e professores requerem sua formação, além de políticas e recursos públicos. Estudos sobre a realidade do atendimento (CAMPOS; FULLGRAF; WIGGERS, 2006; NASCIMENTO et al., 2011) revelam que, quanto às políticas públicas, o atendimento inspirado na concepção de criança indivisível, cidadã, sujeito de direitos, é ainda um direito a ser conquistado para todas as crianças e, para isso, entre outras medidas, a formação profissional deve ser encarada com seriedade.

Nascimento (2011) afirma que a formação e a valorização dos profissionais são aspectos que promovem parte das condições para a ocorrência de atendimento mais adequado à pequena infância, alertando que a qualidade dos serviços prestados às crianças está na dependência de profissionais bem formados.

Obtendo reflexões no que diz respeito ao estudo, Silva (2000) afirma que a formação continuada é uma atividade sequencial, que ocorre ao longo da carreira docente após uma certificação profissional primeira, e que é oferecida àqueles que já possuem uma experiência de ensino. Segundo Pimentel (2004), esse tipo de formação nasceu das atividades de treinamento e aperfeiçoamento desenvolvidas nas décadas de 1940 a 1970, nas quais predominava o caráter compensatório, buscando-se, principalmente, corrigir lacunas da formação inicial. 
Por sua vez, a formação continuada pode oferecer instrumentos de análise das práticas dos profissionais e fomentar a cultura da reflexão como uma marca da ação pedagógica com crianças. Salienta Giovani (1998, p. 47):

Trata-se de reconhecer que a formação de professores e especialistas de ensino [...] se constrói [...] pelo aprendizado e exercício, individual e coletivo, da reflexão crítica sobre as práticas e os contextos de trabalho oportunizando a reconstrução da identidade profissional e pessoal. Trata-se, ainda, de reconhecer a importância do "saber da experiência" e das oportunidades de troca de experiências ou "partilha de saberes" [..].

No que diz respeito à conquista de um atendimento infantil de qualidade, o gestor deveria (co)ordenar as ações de elaboração, execução e avaliação da proposta pedagógica e curricular da creche, a partir do consenso sobre qualidade presente nos Parâmetros Nacionais de Qualidade para a Educação Infantil (2006), na Lei de Diretrizes e Bases da Educação Nacional (1996), no Plano Nacional de Educação (2001), na Política Nacional de Educação: pelo direito das crianças de zero a seis anos à Educação (2006) e nas Diretrizes Curriculares Nacionais para a Educação Infantil (2009), por exemplo.

Art. $4^{\circ}$ As propostas pedagógicas da Educação Infantil deverão considerar que a criança, centro do planejamento curricular, é sujeito histórico e de direitos que, nas interações, relações e práticas cotidianas que vivencia, constrói sua identidade pessoal e coletiva, brinca, imagina, fantasia, deseja, aprende, observa, experimenta, narra, questiona e constrói sentidos sobre a natureza e a sociedade, produzindo cultura (BRASIL, 2009).

Outros aspectos importantes para que o gestor alcance melhores resultados em suas ações são a coerência entre discurso e ações e a confiança depositada no grupo que atua na creche. A vigilância precisa ser abandonada, mas o acompanhamento do grupo não, pois o ser humano é contraditório, inacabado e passível de errar, e a instituição deve responder socialmente pelo trabalho que realiza (VASCONCELOS, 2002).

Essa perspectiva dimensiona o papel do gestor, que teria a função de ajudar os profissionais a vencer as resistências à mudança de forma construtiva. Profissionais responsáveis pela gestão têm o papel de influenciar os outros a utilizar toda a sua capacidade, a realizar suas tarefas e atingir os objetivos da educação proposta, criando uma nova cultura de organização da creche para o trabalho pedagógico a partir da análise de quem é a criança/o que é a infância, o que é cuidar e educar em ambientes coletivos e da definição da prática educativa que se quer construir para o atendimento da primeira infância. 
Por esses e outros motivos, a formação profissional do gestor deveria se pautar na investigação, na experiência e no aperfeiçoamento, em parcerias com universidades, fóruns, com as secretarias municipais de educação, entre outras, pois as propostas de formação continuada têm sido ineficazes em promover a reflexão sobre a prática e renová-la, porque geralmente se organizam como cursos esporádicos (NUNES; CORSINO, 2009; NUNES; CORSINO; DIDONET, 2011).

Em decorrência, uma proposta de formação continuada de gestores de creche precisa abordar de forma consistente os elementos da gestão democrática, o que pode auxiliar os profissionais no cumprimento das duas funções complementares e indissociáveis: cuidar e educar. Por outro lado, deve buscar a superação da função exclusivamente assistencial. Bondioli (2004) afirma que o coordenador pedagógico tem um papel essencial na manutenção dos padrões de qualidade do atendimento infantil. Nos municípios brasileiros, não é suficientemente claro para os gestores o que Bondioli (2004) ressalta, intensificando-se o desafio de traduzir os direitos infantis e o composto educação/cuidados em práticas educativas de alta qualidade (NASCIMENTO, 2011). Cabe ao município, por meio dos profissionais vinculados à educação infantil, a sua gestão, além da elaboração, desenvolvimento e acompanhamento da proposta pedagógica e curricular. Como afirma Kramer (apud MACHADO, 2002), vimo-nos diante da urgência em saber implementar políticas públicas de formação profissional, cultural, política. Mas existe a necessidade de recursos públicos, ética, vontade política etc. (NUNES; CORSINO; DIDONET, 2011).

Kramer (apud MACHADO, 2002, p. 119) afirma que a "a história contada e a prática refletida são a substância viva dos processos de formação", sublinhando a importância política de que a formação profissional tenha um caráter também de formação cultural. Aponta que a teoria, as pesquisas, as reflexões se interligam, se entrelaçam aos conhecimentos advindos das experiências vividas, aos saberes que vêm da prática, e que a formação acontece em diferentes espaços e tempos. Na defesa da formação, indaga:

Podem os processos de formação gerar ou desencadear mudanças? Considero que [...] as práticas concretas feitas nas creches, [...], e aquilo que sobre elas falam seus profissionais são o ponto de partida para as mudanças [...]. [...] feitas em conjunto (KRAMER apud MACHADO, 2002, p. 129).

Em sua análise, rechaça receitas ou manuais no processo de formação de profissionais de educação infantil, sustentando que o eixo deve ser a prática 
coligada à reflexão crítica, tomando a linguagem como recurso essencial para promover a reflexão, a ação recíproca e a conversão dos processos de formação em espaços de pluralidade de vozes e aquisição da palavra.

Nessa perspectiva, o objetivo central de processos formativos dessa natureza é a mudança das pessoas envolvidas, com consequências nas atitudes profissionais:

\section{[...] ao contrário da formação inspirada no modelo escolar, as práticas formativas articulam-se com as situações de trabalho e os quotidianos profissionais, organizacionais e comunitários das escolas. A criação de ambientes formativos com caráter permanente é o seu horizonte, tendo em vista o desenvolvimento humano de todos quantos nele participam. Neste sentido, uma perspectiva de formação em contexto reclama de todos um papel ativo de construtores de saber e não de meros consumidores passivos de programas de formação e “créditos” correspondentes (OLIVEIRA-FORMOSINHO; FORMOSINHO, 2001, p. 73).}

Tal experiência segue na direção do que os autores referem e tem presente que os direitos da criança, atrelados ao papel do profissional, devem produzir a formação continuada.

Dessa forma, vemos que, em nossa realidade, a educação infantil pressupõe desafios aos profissionais e, provavelmente, o maior deles seja o entendimento do significado do educar, do ensinar e do aprender, com fundamento em um novo olhar sobre os intercâmbios cotidianos nas creches.

Nunes e Corsino (2009, p. 25) ressaltam que há uma convergência mundial em defesa da institucionalização da primeira infância, perguntando se é possível “[...] fazer desta convergência, típica de um mundo cada vez mais globalizado, a diminuição das desigualdades entre as populações infantis?”. Assim, a nova institucionalização da infância implica a qualidade do atendimento infantil, a qual ocorre por meio da coordenação de várias ações, a saber: a adequação dos espaços físicos e tempos para o desenvolvimento de uma proposta pedagógica ajustada às crianças pequenas, ao trabalho articulado dos profissionais, à gestão competente, às famílias e comunidades envolvidas e, acima de tudo, à criança como centro da atenção.

Cabe lembrar que a Constituição Brasileira de 1988, com destaque ao artigo 227, e, posteriormente, a LDBEN/1996, seguida das DCNEIs (1999, 2009), reconhecem que as crianças são sujeitos de direitos, de sorte a desencadear um processo de transferência da responsabilidade do atendimento de cuidados e educação das crianças pequeninas para o setor educacional, reforçando o processo de institucionalização da primeira infância. 
Este contexto traz muitas responsabilidades aos gestores em exercício nas creches públicas brasileiras, o que explicita a relevância de estudos como o presente que se fundamenta nas legislações educacionais vigentes, especificamente na Lei de Diretrizes e Bases Nacional (LDBEN/96) e nas Diretrizes Curriculares Nacionais para a Educação Infantil de 2009 (DCNEls), além de estudos na área que se voltam para a necessidade de alta qualidade no atendimento infantil nas creches.

Conforme a LDBEN no 9.394/96, a educação infantil constitui a primeira etapa da educação básica e dispõe que o profissional que atuará com a criança de creche e pré-escola é o professor. As DCNEls de 1999 e 2009 destacam a necessidade de elaborar práticas educativas de qualidade vinculadas às ações dos professores que atuam junto às crianças de 0 a 6 anos.

Nesse contexto normativo, os profissionais são desafiados a construir novas práticas no cotidiano das creches e pré-escolas. Conhecer a criança e a sua especificidade, dimensionar o trabalho pedagógico do professor são condições indispensáveis para a construção de uma proposta pedagógica e curricular específica para o atendimento infantil em creche. No entanto, para isso, é necessário analisar algumas concepções, como a de formação continuada, que interferem nas escolhas e atitudes dos profissionais responsáveis pela coordenação do trabalho pedagógico junto aos profissionais em exercício nas creches da região.

\section{Objetivos}

O presente trabalho se organiza em torno dos seguintes objetivos:

1. Apresentar se o processo formativo e as práticas educativas adotadas pelo Forpedi/Undime sobre formação continuada são capazes de imprimir alterações na compreensão que os gestores têm sobre o trabalho com as crianças entre 0 e 3 anos atendidas nas creches participantes.

2. Estudar o perfil acadêmico e profissional do grupo investigado.

3. Analisar o sentido que os participantes atribuem à formação continuada da qual participam. 


\section{Metodologia}

A presente investigação tem como escolha metodológica a abordagem qualitativa (BOGDAN; BIKLEN, 1994) para desenvolver uma pesquisa colaborativa (BORTONI-RICARDO, 2008; PIMENTA, 2005; GARRIDO; PIMENTA, 2000; GIOVANI, 1998). É uma modalidade de investigação qualitativa de caráter hermenêutico e emancipatório em que profissionais da educação e pesquisadores assumem, conjuntamente, a responsabilidade de problematizar, refletir e transformar as práticas educativas vigentes. É uma forma de trabalho que não tem a intenção de que o professor universitário, considerado especialista, defina por si mesmo os rumos das mudanças, e que os profissionais da creche/pré-escola sejam executores. Trata-se de um instrumento adequado para realizar um projeto de formação continuada, visando à construção da emancipação teórica e prática de todos, de tal modo que favoreça o desenvolvimento profissional em direção a um tipo de ação reflexiva. Segundo Giovani (1998), pretende-se que essa formação ofereça instrumentos de análise das práticas dos profissionais e que a cultura da reflexão seja uma marca da ação pedagógica junto aos participantes. A autora ressalta que os estudos apontam resultados ou efeitos positivos da realização de projetos de pesquisa colaborativa para o desenvolvimento profissional de professores, tais como:

- Criam uma estrutura que facilita a reflexão e a ação sobre as desordens do ensino e os problemas escolares.

- A estrutura colaborativa une e encoraja novas interações, gera possibilidades de os professores assumirem novos papéis e exibirem lideranças.

- Os problemas que ocorrem com professores em suas escolas se revelam muito mais nesse tipo de pesquisa do que na tradicional.

- A pesquisa colaborativa legitima o conhecimento prático dos professores e sua definição dos problemas, tanto para a pesquisa quanto para o desenvolvimento profissional da equipe.

- Tanto o processo de interação do grupo quanto o conteúdo do que é aprendido estreitam a lacuna entre "fazer pesquisa" e "implementar achados de pesquisa”.

Os dados ora apresentados foram obtidos por meio de questionários aplicados em abril de 2013 que continham perguntas fechadas e abertas, organizados com 27 questões, divididas em quatro partes: caracterização pessoal, trajetória escolar, formação continuada e opinião pessoal. A caracterização pessoal foi composta por três questões: idade, sexo, tempo de serviço/ experiência profissional. 
A parte sobre trajetória escolar foi composta por sete questões, sendo todas fechadas.

Já a parte sobre formação continuada foi composta por quatro questões, sendo todas fechadas, que focavam a proposta curricular do município, as dificuldades na organização do trabalho pedagógico de formação e a formação que o município proporcionava para estes profissionais.

O último tópico, sobre as opiniões pessoais, foi composto por 12 questões abertas e uma fechada. Envolvia a função da creche, as diferenças entre as crianças que frequentavam a creche pública e a creche particular, o porquê de as crianças irem à creche hoje e as concepções de criança, cuidar e educar, o adulto que trabalha na creche diretamente com as crianças, proposta pedagógica e curricular da creche, infância, gestor e formação continuada.

As questões para a entrevista foram elaboradas considerando a perspectiva da entrevista reflexiva com base em interrogações que surgiram na análise documental de anos anteriores. Pela análise dos dados obtidos por meio deste questionário podemos compreender a realidade expressa por cada município quando se trata de formação continuada.

0 público-alvo deste estudo foram 86 gestores de creches (orientadores pedagógicos, diretores, supervisores e coordenadores de creche) vinculados a 32 municípios dos polos regionais da Undime de Presidente Epitácio e Presidente Prudente, embora apenas 76 tenham respondido aos questionários.

Posteriormente, os dados obtidos foram tabulados e organizados em categorias para análise. Para esta comunicação, selecionamos a questão: Formação continuada é...?

\section{RESULTADOS PARCIAIS E DISCUSSÃO}

O grupo aqui investigado apresenta o seguinte perfil:

- $100 \%$ são do gênero feminino;

- a maioria dos participantes tem menos de 40 anos, e $23,7 \%$ do grupo têm entre 41 e 45 anos;

- $69,5 \%$ são casados;

- $\quad 20,3 \%$ são professores ocupando função de gestores;

- 37,4\% exercem função de coordenação, embora com denominações diferentes, nos vários municípios;

- $20,3 \%$ são diretores, sendo o restante do grupo distribuído entre 
dirigentes municipais, supervisores e assessores municipais;

- todos são funcionários públicos municipais;

- 45,7\% têm entre 5 e 15 anos de tempo de serviço na área educacional;

- $\quad 50 \%$ têm experiência como professores na educação infantil;

- 30,5\% têm entre um e dez anos de experiência na função de orientação/ coordenação pedagógica e 18,7\% têm o mesmo tempo de experiência na função de diretor;

- 93,2\% possuem curso superior em Pedagogia;

- $\quad 57,6 \%$ fizeram algum tipo de curso de pós-graduação em nível de especialização.

Para a análise dos dados coletados por meio dos 76 questionários devolvidos pelos participantes no início de 2013, as respostas foram agrupadas conforme o sentido atribuído pelo respondente, o que nos permitiu chegar a conjuntos de respostas, como pode ser observado a seguir. Os resultados obtidos até o momento demonstram que a maioria dos gestores municipais entende formação continuada como sendo a continuidade nos estudos de formação adquiridos.

Dessa forma, podemos concluir que os gestores apresentam algum tipo de visão sobre o que é formação continuada, conforme apresentado na Tabela 1, mas somente sete sujeitos articulam uma explicação mais complexa do processo: "Significa renovação, discussão, mudanças e aprofundamento do conhecimento de forma continuada".

Um grupo de 23 sujeitos respondeu que formação continuada é dar continuidade aos estudos de formação adquirida, conceito este semelhante ao de SILVA (2000), que afirma que a formação continuada é uma atividade sequencial, que ocorre ao longo da carreira docente, após uma certificação profissional primeira, e que é oferecida àqueles que já possuem uma experiência de ensino.

Outros 20 sujeitos apresentam a visão de formação continuada relacionada à ideia de aperfeiçoamento, embora apenas dez dentre estes caracterize em que áreas decorreriam o aperfeiçoamento - nos âmbitos pessoal e profissional. 
Contudo, pudemos perceber que os gestores participantes desta investigação ainda não compreendem a formação continuada como relacionada à prática docente ou de gestão e como um encargo de sua função como gestor de creche. Ao observar o perfil do grupo, é possível dizer que a formação inicial e as experiências profissionais não favorecem uma visão mais articulada sobre formação continuada? Como será que esses profissionais desenvolvem a formação continuada em seus municípios? Respostas só serão possíveis após mais um percurso da pesquisa.

Estes resultados, mesmos parciais, nos levam a refletir sobre alguns dos fatores que têm contribuído para a baixa qualidade da educação infantil, em geral, como o relacionado à formação insuficiente do pessoal, aliado à forma como a instituição se organiza para o trabalho pedagógico e administrativo, o que nos faz pensar sobre o trabalho do gestor de creche. Persiste a ausência de proposta pedagógica e curricular específica para crianças pequenas, além da concepção de educação ancorada na ideia de prevenção/compensação de supostas carências diversas, do conceito de criança baseada numa infância a-histórica, desvinculada de uma classe social, considerada incapaz de aprender e carente, por causa do seu ambiente familiar e social. Kuhlmann Júnior (apud FARIA; PALHARES, 2001, p. 204) já referia: “A passagem para o sistema educacional não representa de modo algum a superação de preconceitos sociais envolvidos na educação da criança pequena". Se tais concepções não são explicitadas e paulatinamente superadas, continuam subjacentes às práticas pedagógicas. Nessa direção, os responsáveis pela formação dos profissionais da creche precisam estar atentos à construção da capacidade de relacionar teoria e prática. Essa necessidade encontra justificativa na qualidade desejada ao atendimento infantil.

Em decorrência, uma proposta de formação continuada de gestores de creche precisa abordar de forma consistente os elementos da gestão democrática (trabalho coletivo, proposta pedagógica etc.), o que pode auxiliar os profissionais no cumprimento das duas funções complementares e indissociáveis: cuidar e educar. Por outro lado, deve buscar a superação da função exclusivamente assistencial. 
Tabela 1 - Resposta dos gestores à questão “Formação continuada é....?”

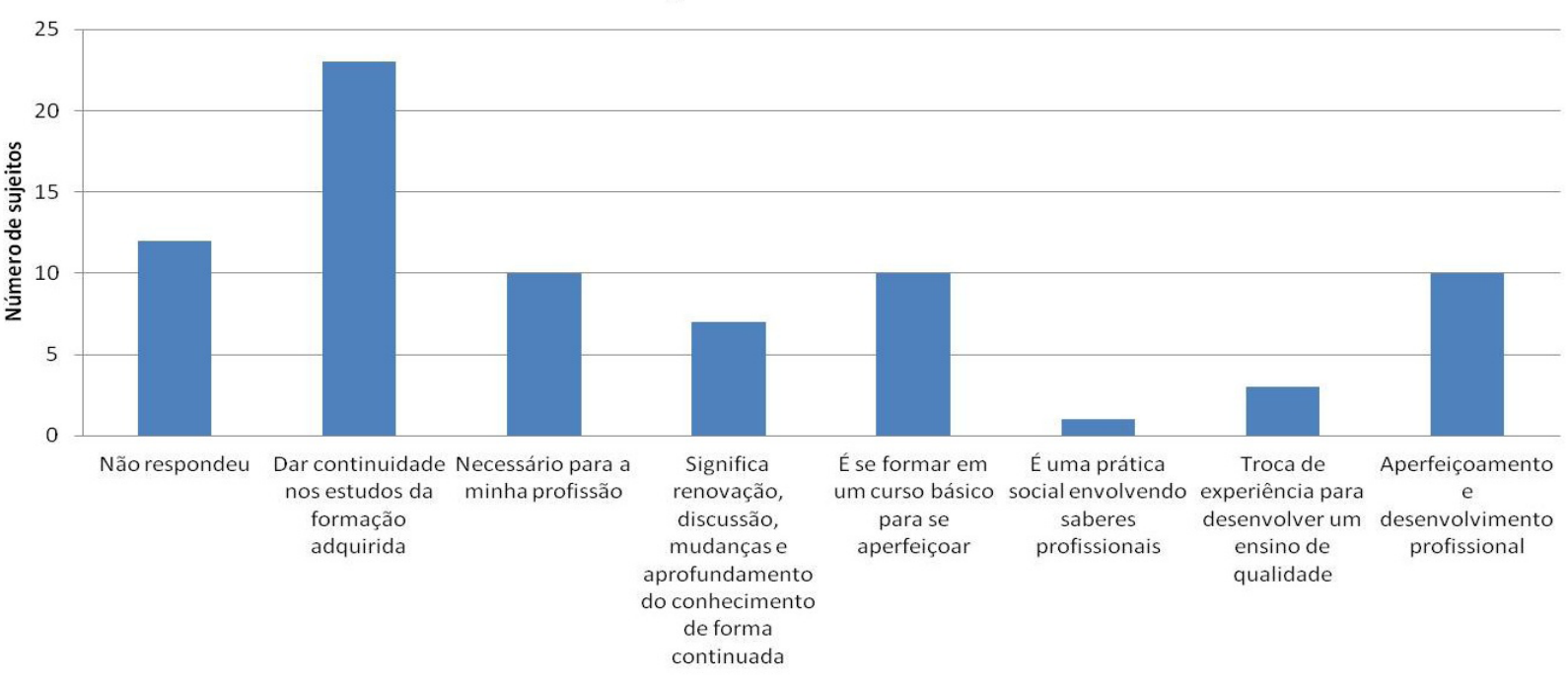

Fonte: Elaborada pelos autores.

Imagens

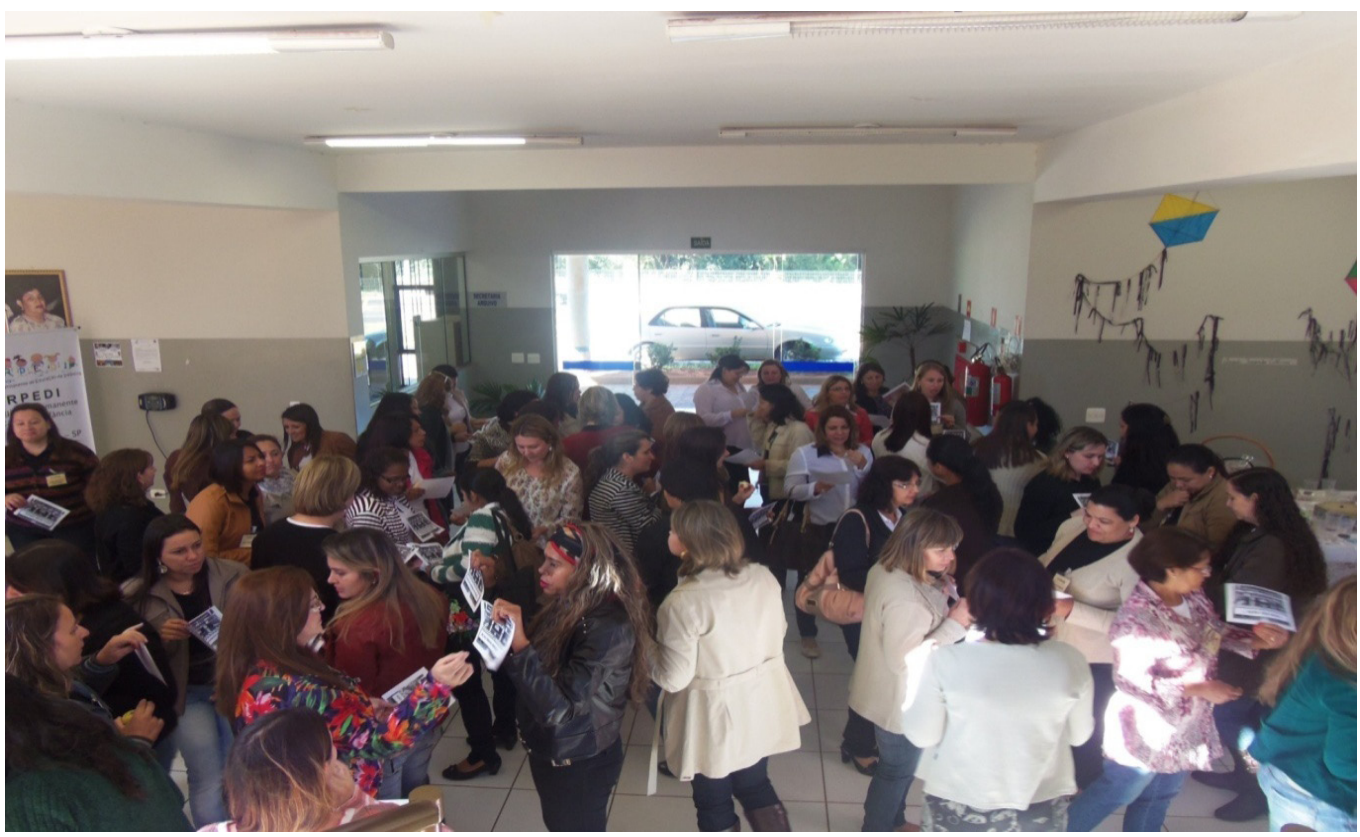

Figura 1. Formação continuada de gestores. Atividade cultural (ago. 2013).

Fonte: Acervo Pessoal - FORPEDI 


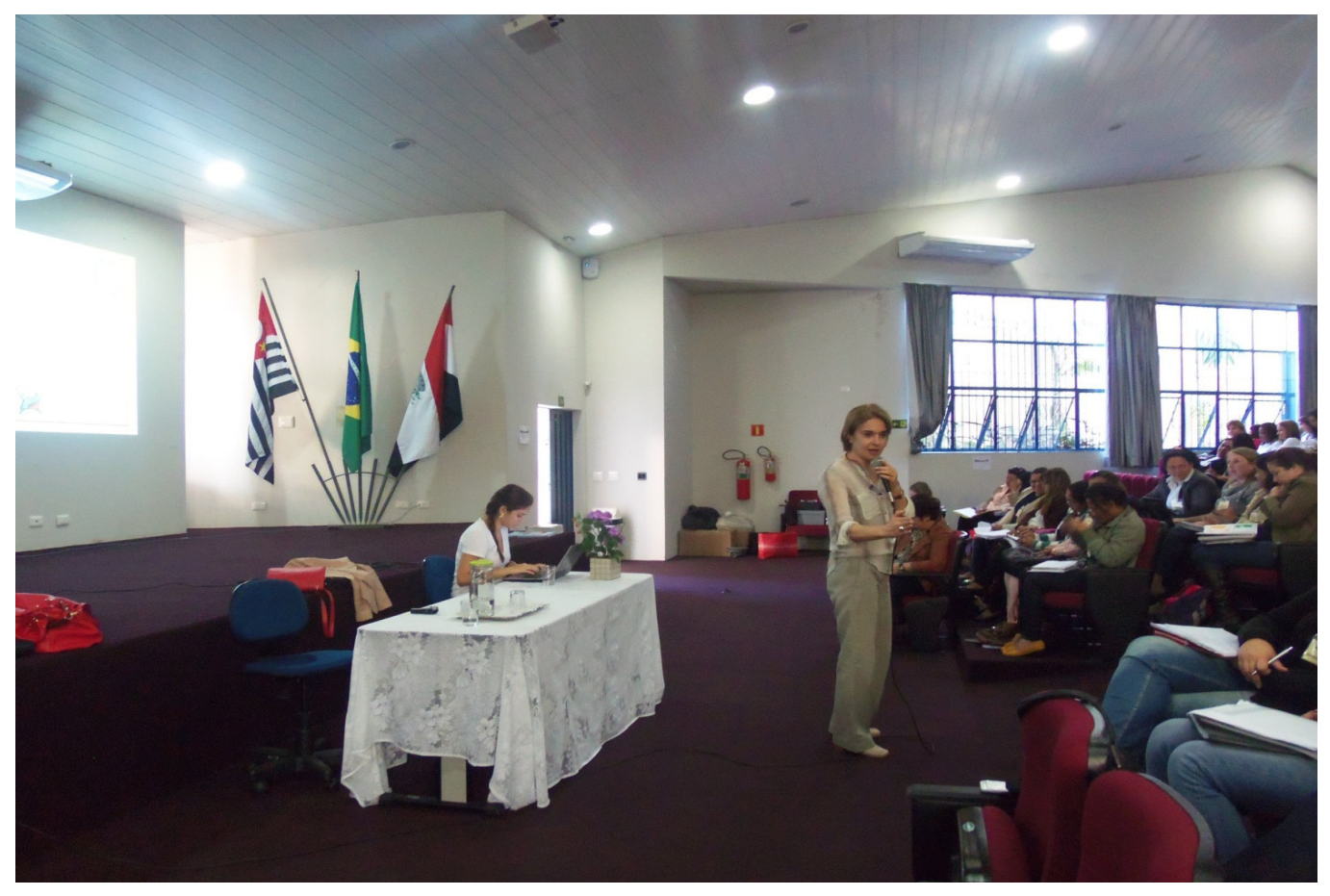

Figura 2. Formação continuada de gestores 2013. Profa. Dra. Célia Maria Guimarães, coordenadora do projeto.

Fonte: Acervo Pessoal - FORPEDI

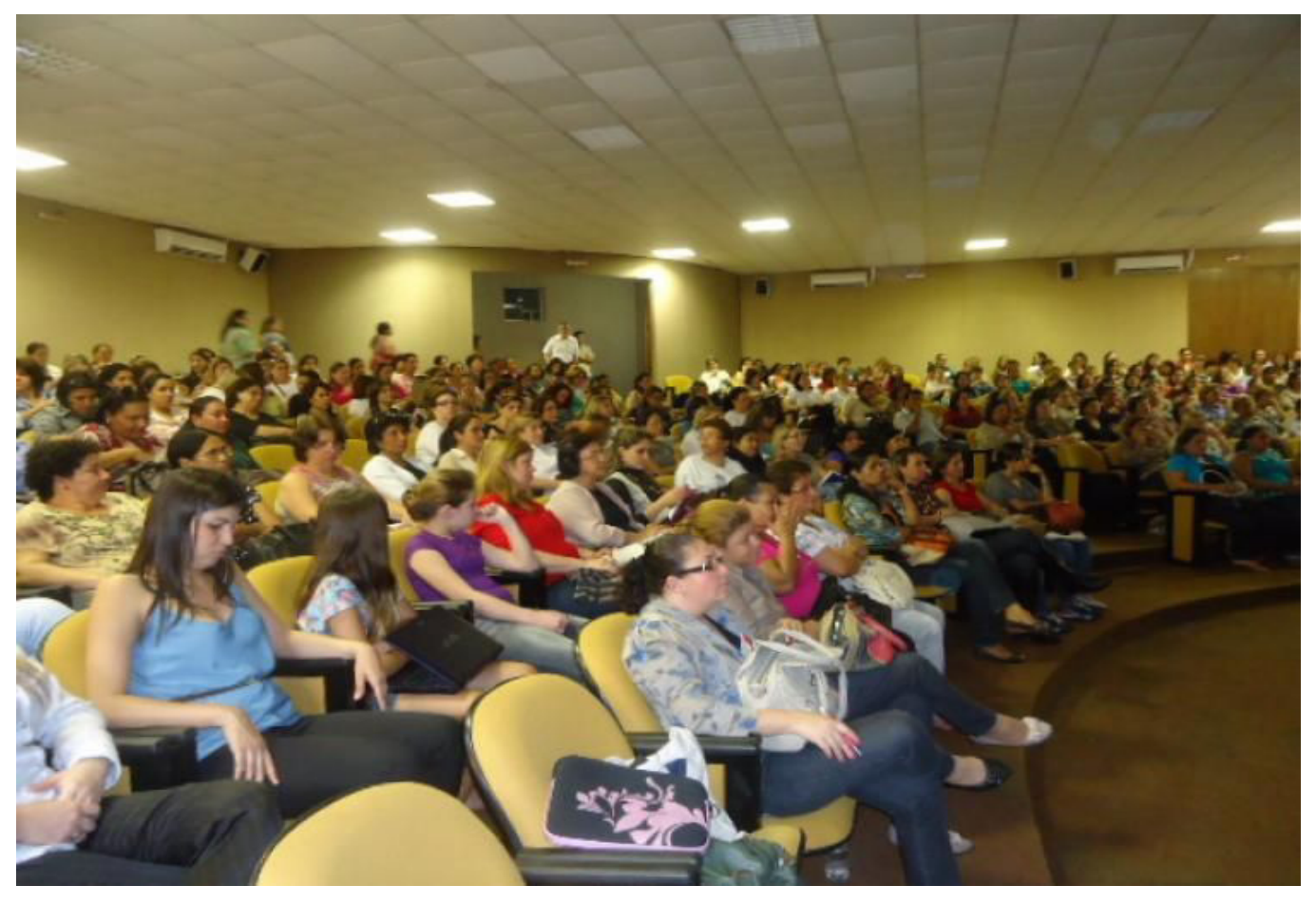

Figura 3. Encontro com a profa. Telma Vinha, Unicamp, 2012.

Fonte: Acervo Pessoal - FORPEDI 


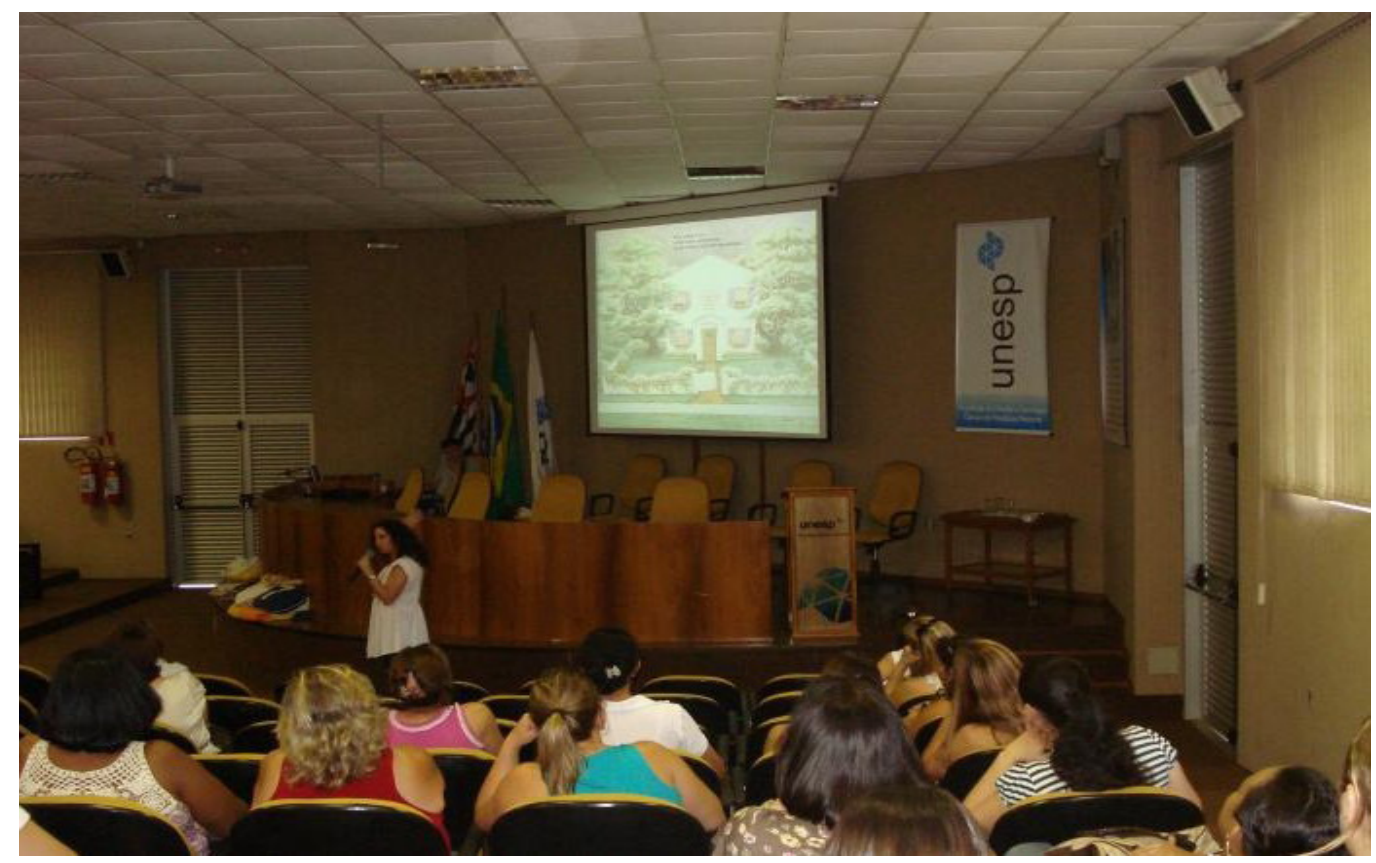

Figura 4. Relato de experiência, Carmem, Rancharia (SP).

Fonte: Acervo Pessoal - FORPEDI

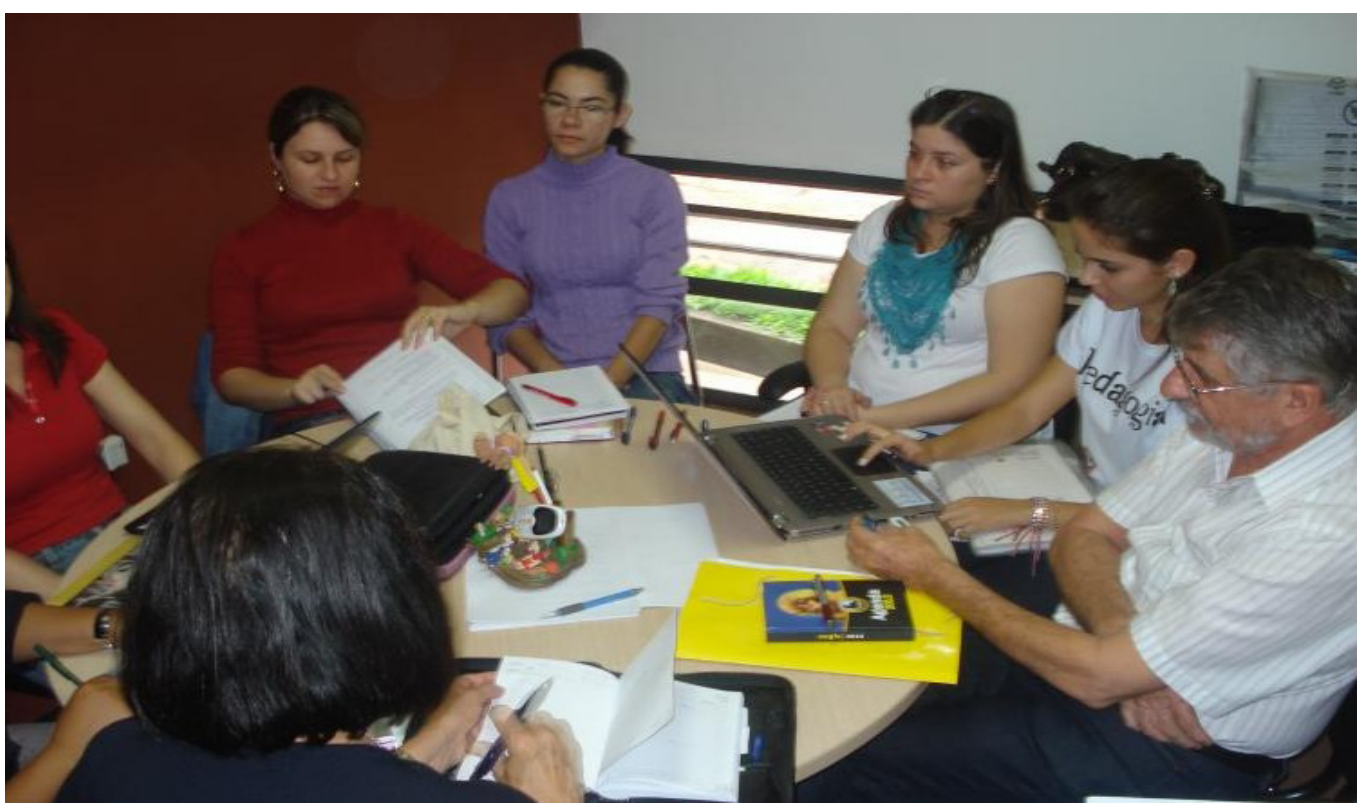

Figura 5. Reunião do grupo gestor, 2012.

Fonte: Acervo Pessoal - FORPEDI 


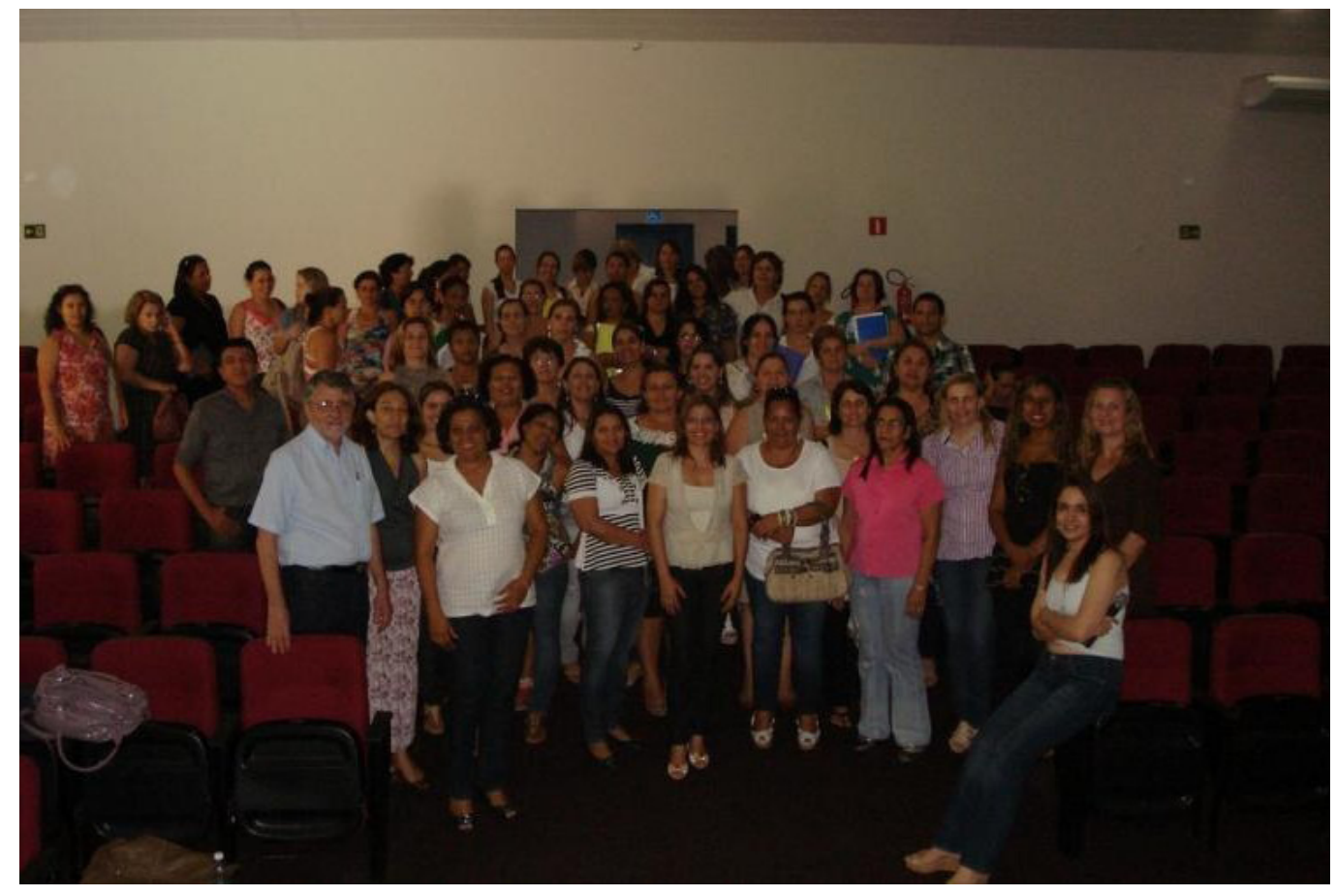

Figura 6. Assembleia de criação da Associação dos Amigos do Forpedi.

Fonte: Acervo Pessoal - FORPEDI

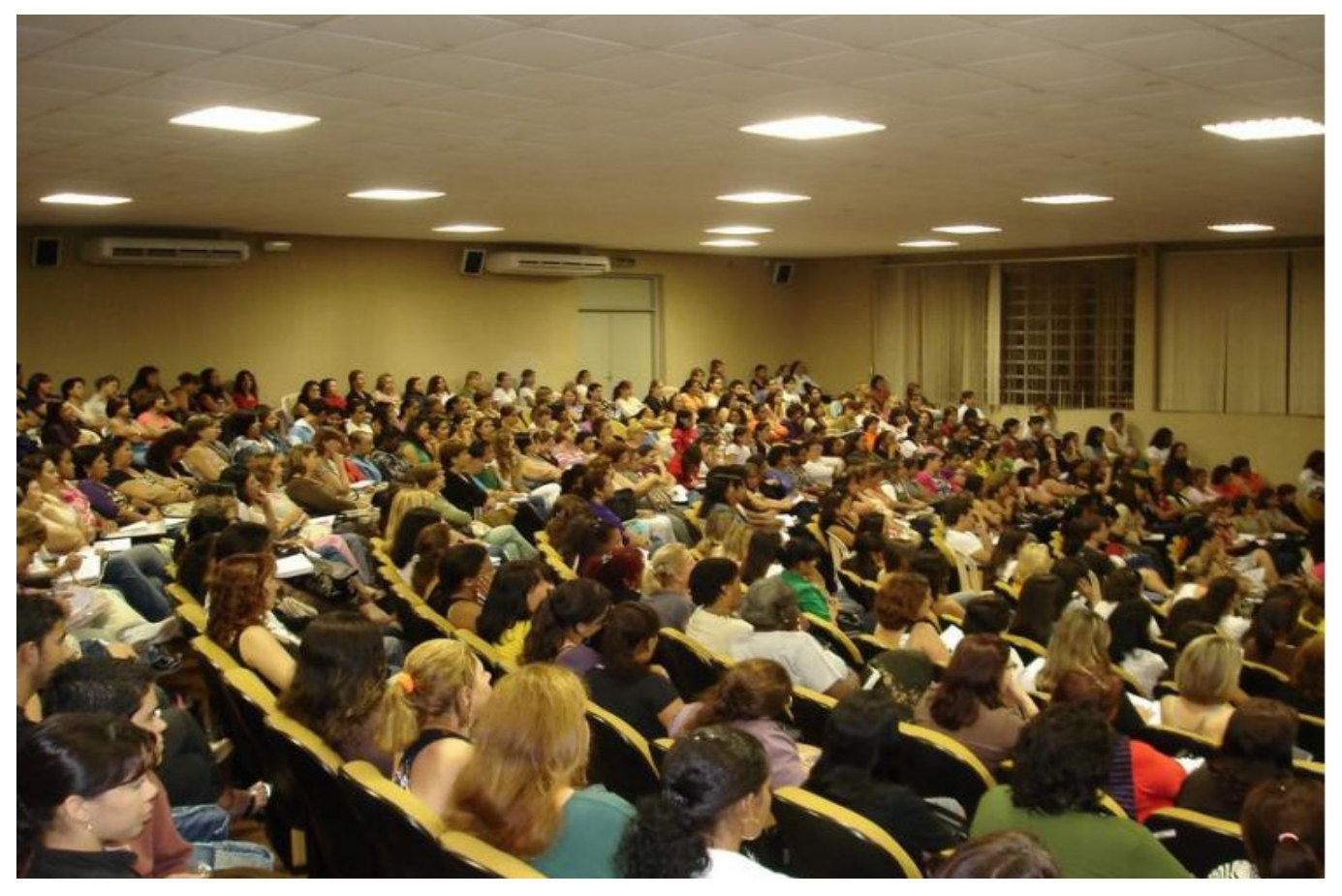

Figura 7. Instalação do Forpedi.

Fonte: Acervo Pessoal - FORPEDI 


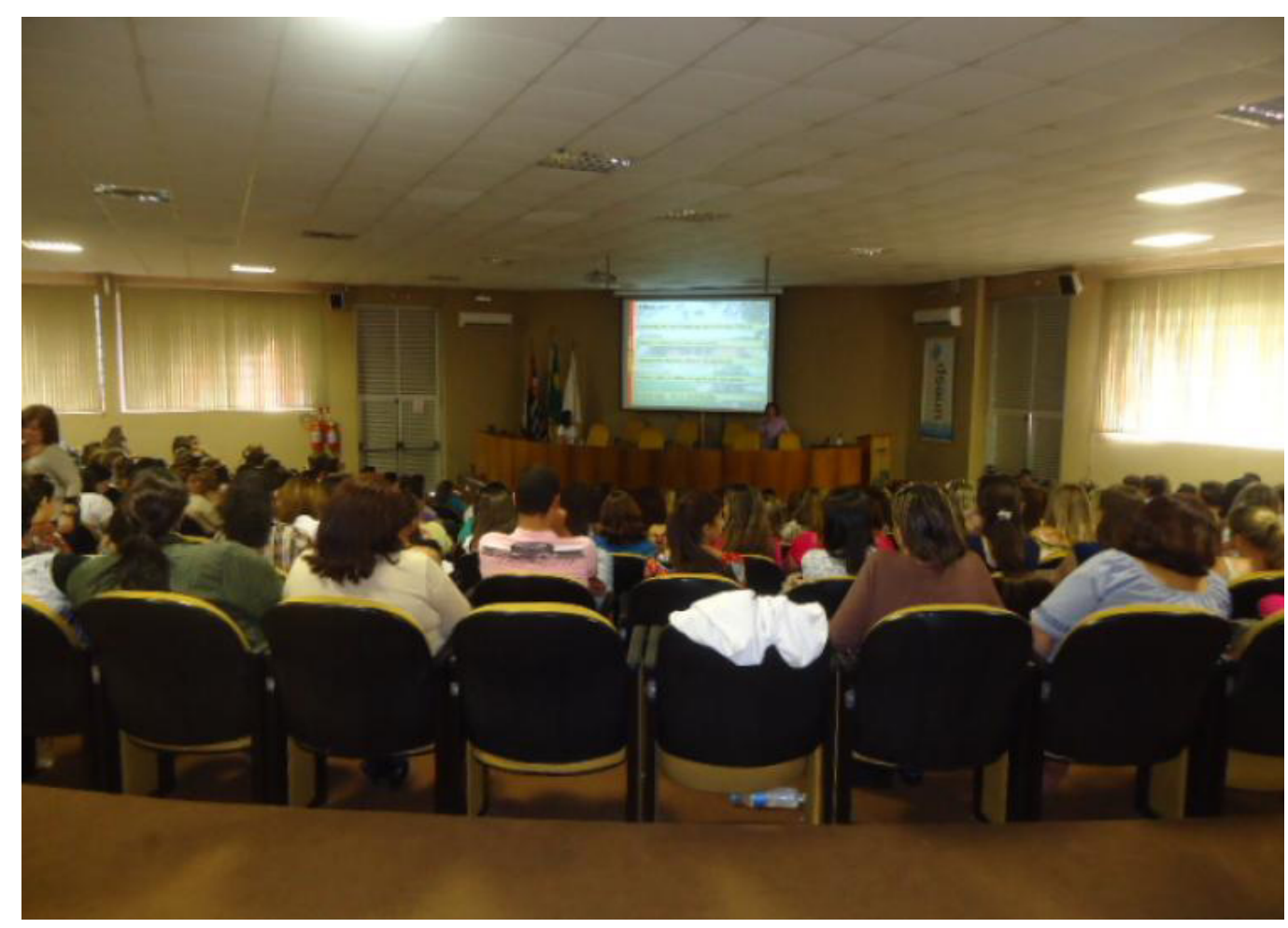

Figura 8. Relato de experiência - trabalho com projetos com bebês, CCI/FCT/Unesp. Fonte: Acervo Pessoal - FORPEDI 


\section{Continuing education: the views of nursery school managers in the region of Presidente Prudente/SP}

Abstract: The present text aims at analyzing the views of public nursery school managers have on continuing education. The partial results are an excerpt from the project supported by PROEX "(UN)TRACKING CHILDHOOD EDUCATION IN THE REGION ...: required policies for quality assistance”, bound to the PERMANENT REGIONAL FORUM OF CHILDHOOD EDUCATION (FORUM REGIONAL PERMANENTE DE EDUCAÇÃO DA INFÂNCIA - FORPEDI), under the agreement of the Union of the Education Public Directors (União dos Dirigentes Municipais de Educação). The analysis of the present work was conducted through data obtained by a questionnaire answered by 76 of the 85 participants, in April 2013. Subsequently, the data obtained were tabulated and organized in categories for further analysis. For this communication the question "What is continuing education...?" was selected.

Key-words: Continuing education. Managers. Nursery school. 
BOGDAN, R. C.; BIKLEN, S. K. Investigação qualitativa em educação: uma introdução à teoria e aos métodos. Porto: Porto Editora, 1994.

BORTONI-RICARDO, S. M. O professor pesquisador: introdução à pesquisa qualitativa. São Paulo: Parábola Editorial, 2008. (Estratégias de ensino, 8).

BRASIL. Lei n 9.394/96, de 20 de dezembro de 1996. Estabelece as diretrizes e bases da educação nacional. Diário Oficial [da] República Federativa do Brasil. Poder Legislativo, Brasília, DF, 23 dez. 1996. p. 27.833. Disponível em: 〈http://portal.mec.gov.br/arquivos/pdf/ldb.pdf〉. Acesso em: 12 jul. 2013.

- Ministério da Educação. Parâmetros Nacionais de Qualidade para a Educação Infantil. Brasília: MEC/SEB, 2006. Disponível em: «http://portal. mec.gov.br/seb/arquivos/pdf/Educinf/eduinfparqualvol1.pdf〉. Acesso em: $1^{\underline{0}}$ set. 2013.

- Ministério da Educação. Secretaria de Educação Básica. Política Nacional de Educação Infantil: pelo direito das crianças de zero a seis anos à educação. Brasília: MEC, SEB, 2006. 32 p. Disponível em: 〈http://www.oei.es/ quipu/brasil/pol_educ_infantil.pdf〉. Acesso em: 1ํㅗ. set. 2013.

Parecer CNE/CEB n 20, de 11 de novembro de 2009. Revisão das Diretrizes Curriculares Nacionais para a Educação Infantil. Diário Oficial [da] República Federativa do Brasil. Poder Legislativo, Brasília, DF, 9 dez. 2009, Seção 1, p. 14. Disponível em: 〈http://portal.mec.gov.br/index. php?option=com_content\&view=article\&id=12745〉. Acesso em: 21 ago. 2013.

Plano Nacional de Educação. 2001. Disponível em: «http://portal. mec.gov.br/arquivos/pdf/pne.pdf〉. Acesso em: 1ํㅗ. 2013.

. Resolução CEB no 1, de 7 de abril de 1999. Institui as Diretrizes Curriculares Nacionais para a Educação Infantil. Diário Oficial [da] República Federativa do Brasil. Brasília, DF, 13 abr. 1999, Seção 1, p. 18. Disponível em: 〈http://www.ufv.br/seg/diretrizes/edi.pdf〉. Acesso em: 21 ago. 2013.

BONDIOLI, A. Dos indicadores às condições do projeto educativo: um percurso pedagógico-político de definição e garantia da qualidade das creches da região da Emília-Romanha. In: BONDIOLI, A. (Org.) 0 projeto pedagógico da creche e a sua avaliação: a qualidade negociada. Campinas, SP: Autores Associados, 2004, p. 14-33. 
CAMPOS, M. M.; FULlGRAF, J.; WIGGERS, V. A qualidade da educação infantil brasileira: alguns resultados de pesquisa. Cadernos de Pesquisa, v. 36, n. 127, p. 87-128, jan./abr. 2006.

GARRIDO, E.; PIMENTA, S. G.; MOURA, M. O. A pesquisa colaborativa na escola como abordagem facilitadora para o desenvolvimento da profissão do professor. In: MARIN, A. J. (Org.). Educação continuada. Campinas, SP: Papirus, 2000. p. 89-112.

GIOVANI, L. M. Do professor informante ao professor parceiro: reflexões sobre o papel da universidade para o desenvolvimento profissional de professores e as mudanças na escola. Cadernos Cedes, Campinas, v. 19, n. 44, p. 46-58, abr. 1998. Disponível em: 〈http://www.scielo.br/scielo.php?script=sci_arttex t\&pid=S010132621998000100005\&lng=pt\&nrm=i\&tlng=pt>. Acesso em: 25 jun. 2013.

KRAMER, S. Formação de profissionais de educação infantil: questões e tensões. In: MACHADO, A. (Org.) Encontros e desencontros em educação infantil. São Paulo: Cortez, 2002, p. 117-132.

KUHLMANN JÚNIOR, M. Educação infantil e currículo. In: FARIA, A. L. G.; PALHARES, M. S. (Org.). Educação infantil pós-LDB: rumos e desafios. 3. ed. Campinas, SP: Autores Associados, 2001.

NASCIMENTO, M. L. Algumas considerações sobre a infância e as políticas de educação infantil. Educação \& Linguagem, São Paulo, v. 14, n. 23/24, p. 146159, jan./dez. 2011.

NUNES, M. F. R.; CORSINO, P. A institucionalização da infância: antigas questões e novos desafios. In: CORSINO, P. (Org.). Educação infantil: cotidiano e políticas. Campinas, SP: Autores Associados, 2009, p. 15-32.

; ; DIDONET, V. Educação infantil no Brasil: primeira etapa da educação básica. Brasília, DF: Unesco, MEC/SEB, Fundação Orsa, 2011.

PIMENTA, S. G. Pesquisa-ação crítico-colaborativa: construindo seu significado a partir de experiências com a formação docente. Educação e Pesquisa, São Paulo, v. 31, n. 3, p. 521-539, set./dez. 2005. Disponível em: http://www. scielo.br/pdf/ep/v31n3/a13v31n3.pdf. Acesso em: 10 jan. 2013.

PIMENTEL, A. Jogo e desenvolvimento profissional: análise de uma proposta de formação continuada de professores. 2004. Tese (Doutorado em Educação) - Faculdade de Educação, Universidade de São Paulo, São Paulo, 2004. 
SILVA, A. M. C. A formação contínua de professores: uma reflexão sobre as práticas e as práticas de reflexão em formação. Educação e Sociedade, Campinas, n. 72, p. 89-109, ago. 2000.

VASCONCELOS, C. dos S. Coordenação do trabalho pedagógico: do projeto político pedagógico ao cotidiano da sala de aula. São Paulo: Libertad, 2002. $213 \mathrm{p}$.

RECEBIDO: Maio de 2014.

APROVADO: Outubro de 2014. 